\title{
Influence of 3-(Trimethoxysilyl) Propyl Methacrylate Coupling Agent Treatment of Olive Pomace Flour Reinforced Polystyrene Composites
}

\author{
Hamida Boussehel \\ Department of Material Sciences, Faculty of Exact Sciences and Sciences of Nature and Life, University of Biskra, Biskra \\ 07000, Algeria
}

Corresponding Author Email: h.boussehel@univ-biskra.dz

https://doi.org/10.18280/rcma.290606

Received: 9 September 2019

Accepted: 15 November 2019

\section{Keywords:}

composite, coupling agent, olive pomace, polystyrene, silane

\begin{abstract}
This paper aims to disclose the effects of surface modification on the morphological, thermal and mechanical properties of olive pomace flour (OPF) reinforced polystyrene composites. First, the OPF was treated by the silane coupling agent: 3-(Trimethoxysilyl) propyl methacrylate (TMSPMA). Then, the treated OPF was added to polystyrene (PS) at different ratios, creating the composite samples. The structural and property changes resulting from this treatment were observed and discussed through Fourier transform infrared spectroscopy (FTIR), morphological analysis, thermal analysis and mechanical analysis. The results show that, with the growing OPF content, the tensile strength and elongation at break of the composites decreased, while the Young's modulus increased; the composites prepared with the silane coupling agent were more thermally stable than the untreated composites; the filler-matrix interaction was improved through the surface modification of the OPF by the TMSPMA).
\end{abstract}

\section{INTRODUCTION}

In recent years great interest in the development of new composites derived from thermoplastic polymer matrices reinforced with wood filler, because of their environmental and economic benefits [1, 2]. Their renewability, biodegradability, low density, high stiffness and relatively low price [3]. Among of these various thermoplastic matrices mainly used in the manufacture of plastic / wood composites was polystyrene [4], which is very popular because of its transparency, fluidity and good electrical insulating properties [5].

The use of lignocellulosic fibers has certain disadvantages such as degradation at low temperatures with poor compatibility between the polar lignocellulosic filler and the non-polar polymer matrix [6]. Due to the strong intermolecular hydrogen bonding between the lignocellulosic fibers, which tend to agglomerate during mixing with the polymer matrix in the compounding process, resulting composites with low mechanical and thermal properties [7].

The improving the interface compatibility between thermoplastic polymers and lignocellulosic filler has attracted much attention from researchers [8]. Several modifications of the fiber surface such as reaction with acid compounds [9, 10], alkali treatment [11, 12] and the incorporation of compatibilizer, such as malleated polymer [13, 14] or treatment with coupling agents $[15,16]$ reported in the literature.

Among the different coupling agents widely used; the organosilane $\left(\mathrm{R}-\mathrm{Si}-(\mathrm{OR})_{3}\right)$. These bifunctional molecules are used to modify the surface of natural fibers with their alkoxysilane groups. Which after hydrolysis are capable of reacting with surfaces rich in $\mathrm{OH}$ groups forming chemical bonds with the surface of the fibers through a siloxane bridge, organofunctional group bonds to the polymer matrix. This group is responsible to improve the compatibilization between the fibers and the polymer matrix by establishing covalent bonds between them. Therefore, the silane coupling agents' function as a bridge between the fibers and the matrix [17-19].

In the present work, polystyrene composites have been prepared by reinforcing untreated and treated olive pomace flour (OPF) with content $0,10,20$ and $30 \%$ wt. The objective is to investigate the effect of used 3(trimethoxysilyl) propyl methacrylate grafted on olive pomace flour as a coupling agent to enhance the interfacial bonding between olive pomace flour and polystyrene on the morphological, thermal and mechanical properties of PS / OPF composites.

\section{MATERIALS AND METHODS}

\subsection{Materials}

In this study, polystyrene (PS) was used as matrix with molar mass $104.15 \mathrm{~g} / \mathrm{mol}$ and $0.04737 \mathrm{KJ} / \mathrm{Kmol}$ heat capacity at $100 \mathrm{~K}$.

Olive pomace flour (OPF) used as filler for polystyrene composites was obtained from the residues of olive oil mill from Biskra region, located in the south of Algeria. It was dried for two weeks and ground into very fine particles. Chemicals used for olive flour treatment include 3(trimethoxysilyl) propyl methacrylate (SilaneA174), acetic acid and ethanol are supplied by Sigma-Aldrich. 


\subsection{Silane treatment}

1wt \% of 3-(trimethoxysilyl) propyl methacrylate, (weight percentage compared to the olive pomace flour) was dissolved in water. The $\mathrm{pH}$ of the solution was adjusted to 4 with acetic acid (to prevent polymerization of the silane to polysiloxane) and stirred continuously during $15 \mathrm{~min}$. Olive pomace flour was soaked in solution for 1 hour at room temperature. Finally, the flour washed with water until a $\mathrm{pH}$ of 7 to remove the excess of silane and then with ethanol and dried in an oven at $80{ }^{\circ} \mathrm{C}$. The probable chemical reaction can be illustrated in the Figure 1.
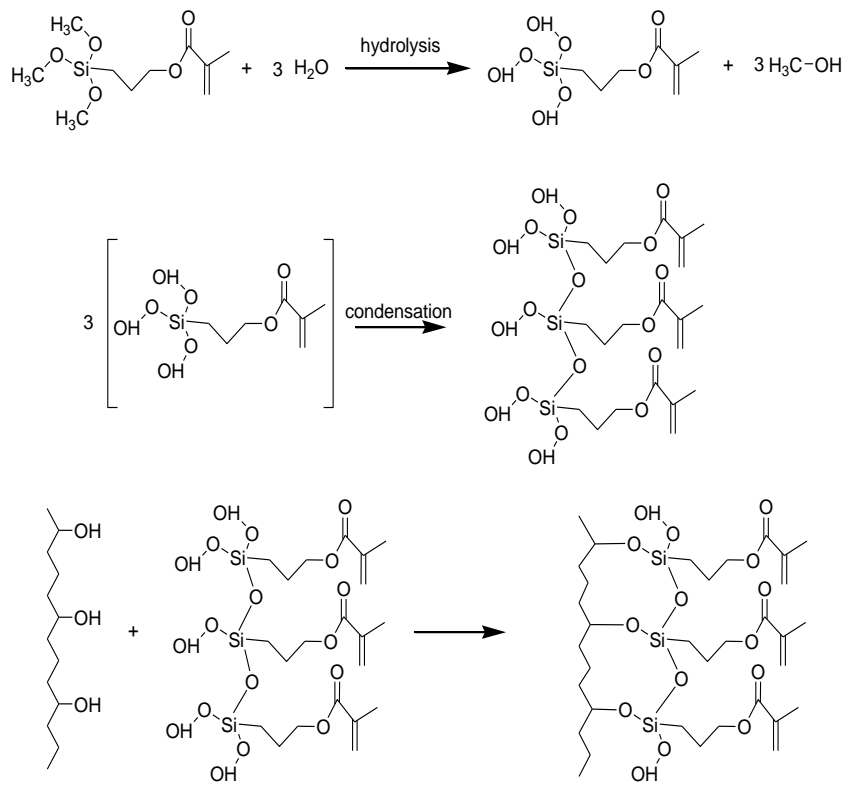

Figure 1. Reaction mechanism of olive pomace flour and 3(trimethoxysilyl) propylmethacrylate

\subsection{Composites processing}

The composite materials PS/ OPF were prepared by mixing the polymer matrix and the flour in a single screw extruder (Plasti-Corder PLE 330) at a temperature of 160$190^{\circ} \mathrm{C}$ and speed of 40 rpm/min. Different formulations of composites were prepared with $0 \%, 10 \%, 20 \%$ and $30 \mathrm{wt} \%$ of loading rate of olive stone.

The strips obtained by extrusion are introduced into the mold and compressed with a hydraulic press (Schwabenthan polystat $300 \mathrm{~S}$ ) at $170^{\circ} \mathrm{C}$ under a pressure of 300 bar during $10 \mathrm{~min}$.

\section{CHARACTERIZATION}

\subsection{Olive stone flour composition}

To know the chemical composition of olive pomace, a succession of extractions it possible to isolate the different substances contained in the material (fats and waxes, cellulose, hemicelluloses and lignin). All tests were performed according to the procedures described in the literature [20].

\subsection{FTIR analysis}

Fourier transform infrared spectroscopy (FTIR-8400S
Shimadzu spectrometer) was used to analysis the possible chemicals bonding existing in the untreated and treated olive flour.

\subsection{Morphological analysis}

The morphology of the virg in PS and the composites were studied using scanning electron microscopy (SEM) with a Quanta FEG250 SEM microscope operating at $2-12 \mathrm{kV}$. The specimens were coated with a $50-100 \mu$ mlayer of gold and carried out under liquid nitrogen.

\subsection{Thermal analysis}

Thermal analysis (Q600SDT instrument) was used to perform thermogravimetric analysis (TGA). An initial mass sample (5-30 mg) was introduced into a platinum crucible. Weight loss of sample is measured under a nitrogen atmosphere of $50{ }^{\circ} \mathrm{C}$ to $600{ }^{\circ} \mathrm{C}$, at a heating rate of $10^{\circ} \mathrm{C} / \mathrm{min}$.

\subsection{Mechanic analysis}

The tensile properties of composites are measured using a tensile machine (Zwick/Roell) according to ISO527-1:2012. For each composite, six tests are performed to calculate the average value.

\section{RESULTS AND DISCUSSION}

\subsection{Olive stone flour composition}

The chemical composition of OPF, given in Table1, confirms the lignocellulosic character of the filler as being composed of lignin, hemicellulose, cellulose, and extractives with contents of about 27\%, 25\%, 31\% and $13 \%$, respectively. The high cellulose content accounts for the strong stiffness of olive nuts and justifies the interest their use as reinforcing filler [21].

Table1. The chemical composition of OPF

\begin{tabular}{cc}
\hline Constituent & Amount (\%) \\
\hline Moisture content & $6.52 \pm 0.02$ \\
Lignin & $27.67 \pm 0.20$ \\
Cellulose & $31.39 \pm 0.06$ \\
Hemicellulose & $25.01 \pm 0.06$ \\
Ash & $2.54 \pm 0.20$ \\
\hline
\end{tabular}

\subsection{FTIR analysis}

FTIR spectra of treated and untreated olive pomace flour are given in Figure 2. The FTIR spectrum of untreated olive stone flour has absorption band at 1746 and $1238 \mathrm{~cm}^{-1}$ that are due to carbonyl $\mathrm{C}=\mathrm{O}$ stretching present in the hemicellulos's lignin and extractives [22]. The intensity of 3430 and $1034 \mathrm{~cm}^{-1}$ peaks assigned to the stretching vibrations of hydroxyl groups of cellulose and $\mathrm{C}-\mathrm{O}$ groups of hemicelluloses [23]. The peak at $1644 \mathrm{~cm}^{-1}$ in the untreated OSF flour is associated with the adsorbed water.

The main change observed after treatment with 3(trimethoxysilyl) propyl methacrylate is the emergence of new bands in the region between 1050 and $1100 \mathrm{~cm}^{-1}$, which are assigned to Si-O-Si and Si-O-OPF stretching. Although this band is not intense and overlaps with those of OPF 
untreated, still their presence is indicative of the silane attachment to the OPF flour [21].

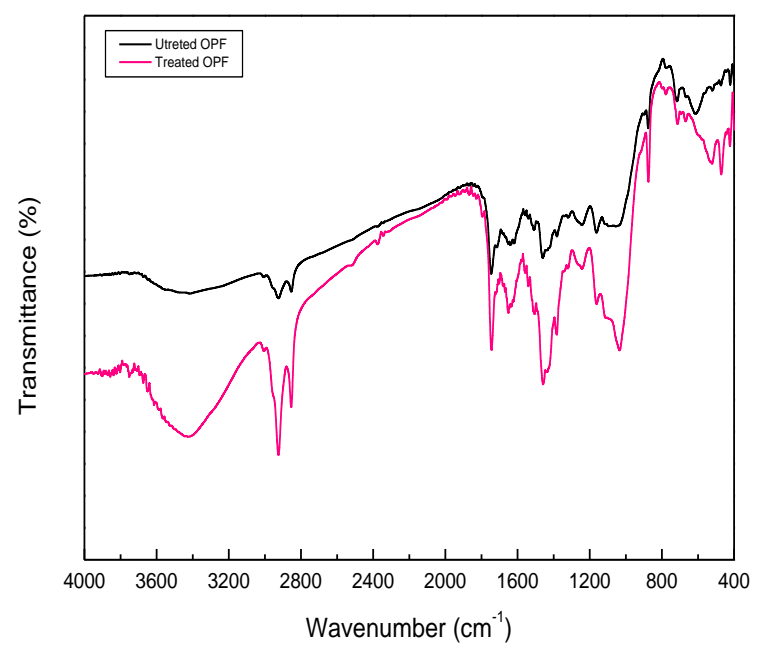

Figure 2. FTIR spectra of treated and untreated filler

\subsection{Morphological analysis}

SEM observations of virgin PS and composites are illustrated in Figure 3.

The matrix of virgin polystyrene (Figure 3a) shows a very smooth and homogeneous surface, whereas for untreated composites (Figure 3b), a rough, irregular and heterogeneous surface is observed with the presence of micro voids and cavities on the surface due to the loosening of the filler during the fracture, due to poor interfacial adhesion and the difference in polarity between the hydrophilic load and the hydrophobic polymer [24].

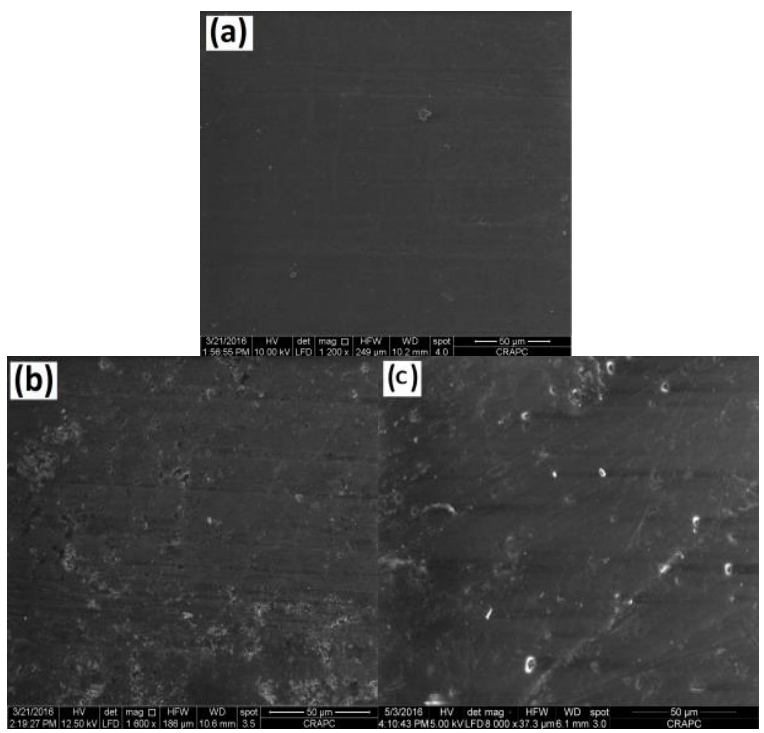

Figure 3. SEM micrographs of PS and composites reinforced with $30 \mathrm{wt} \%$ of filler: (a) virgin PS (b) untreated composites $\mathrm{F}_{30 \mathrm{UT}}$; (c) treated composites $\mathrm{F}_{30 \mathrm{ST}}$

Composites with olive pomace flour treated with 3(trimethoxysilyl) propyl methacrylate (Figure 3c) reduce flour detachment. Empty spaces are smaller or disappeared most of the time. The coupling agent improved the interfacial bond between the fiber and the matrix. This improvement leads to good wettability between the fiber and the matrix, reflected in a better dispersion of flour particles and a decrease in the polarity of the filler [25].

\subsection{Thermal analysis}

The thermograms of weight loss (ATG) and derivative weight loss (DTG) of PS and composites are presented in Figure $4 \mathrm{a}$ and $4 \mathrm{~b}$. For untreated composites, it is clear that the thermal degradation profiles are similar. We record one degradation stage for polystyrene attributed to its depolymerization [11], compared to untreated composites; the degradation is done in two stages due to the presence of the filler. The incorporation of untreated flour into the polymeric matrix leads to a decrease onset decomposition. It is $380{ }^{\circ} \mathrm{C}$ for virgin PS, $358.9{ }^{\circ} \mathrm{C}, 329.1{ }^{\circ} \mathrm{C}$ for composites at a loading rate of 10 and $30 \%$ respectively. This decrease attributed to the presence of cellulose, hemicellulose and lignin in the flour [26]. Ataround $484^{\circ} \mathrm{C}$, stability is recorded attributed to the formation of mineral residue. On the other hand, for composites treated with a coupling agent have again in the onset decomposition to untreated composites, it is estimated at $368.8^{\circ} \mathrm{C}$ and $356.9^{\circ} \mathrm{C}$ for the $F_{10 S T}$, and $F_{30 S T}$ formulations respectively.
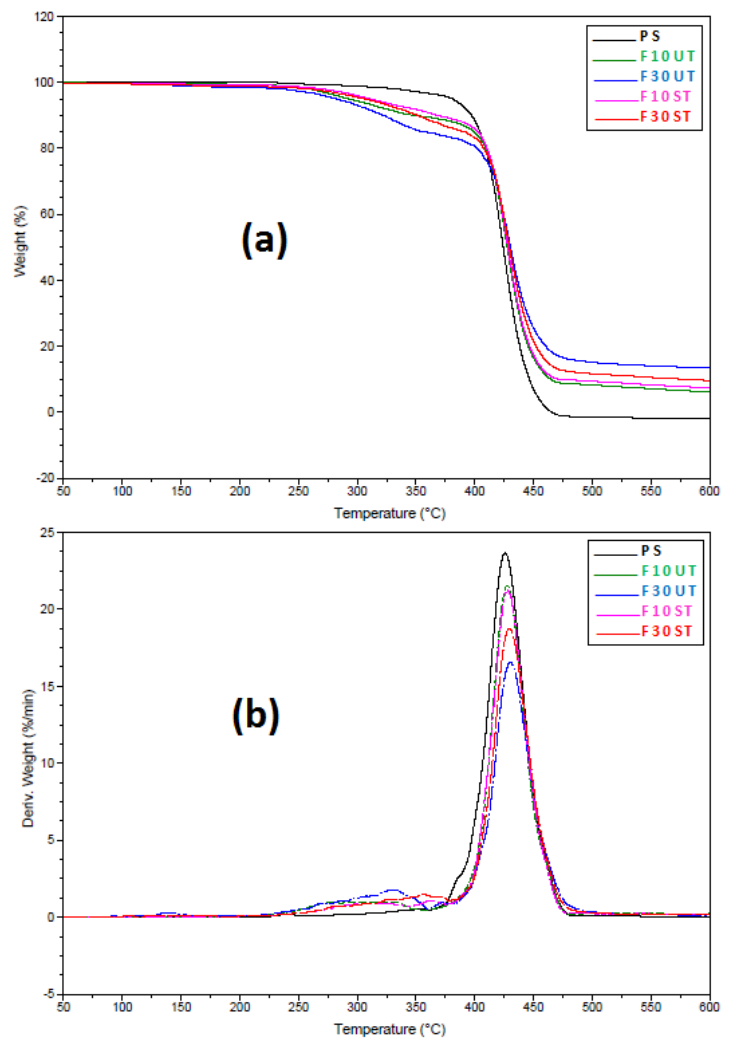

Figure 4. The thermograms of weight loss (ATG) and derivative weight loss (DTG) of PS and composites

The DTG thermograms of the composites (Figure 4b) show the appearance of the different peaks. A first peak appears around $90-120{ }^{\circ} \mathrm{C}$ which corresponds to the evaporation of the water adsorbed on the surface of the flour particles, this is attributed to the hydrophilic nature of the untreated flour which has the ability to absorb more water molecules. On the other hand, in the same temperature, polystyrene does not record any peaks, a sign of the hydrophobic nature of the PS matrix. A second peak corresponding to the thermal degradation of hemicellulose, 
cellulose and lignin is located between $200{ }^{\circ} \mathrm{C}$ and $380{ }^{\circ} \mathrm{C}$ [27]. For polystyrene, a single wide peak appears between $380-475^{\circ} \mathrm{C}$ corresponding to its decomposition.

The incorporation of untreated olive pomace flour leads to a decrease the onset degradation, and to a reduction in the maximum rate of decomposition. It is estimated at $23.16 \% / \mathrm{min}$ for PS and $21.56-16.55 \% / \mathrm{min}$ for $\mathrm{F}_{10 \mathrm{NT}}$, and
$\mathrm{F}_{30 \mathrm{NT}}$ formulations respectively, with maximum degradation temperatures at $427.5{ }^{\circ} \mathrm{C}$ and $430.2{ }^{\circ} \mathrm{C}$ which are significantly higher compared to virgin PS at $425.7^{\circ} \mathrm{C}$. It can be clearly seen that the lignocellulosic load significantly delays the degradation of polystyrene; it acts as an inhibitor of thermal degradation. Thermal parameters are derived and summarized in Table 2.

Table 2. Thermal degradation and derivative weight loose of composites

\begin{tabular}{lccccc}
\hline Sample designation & $\mathbf{F}_{\mathbf{0}}$ & $\mathbf{F}_{\text {10UT }}$ & $\mathbf{F}_{\text {30UT }}$ & $\mathbf{F}_{\text {10ST }}$ & $\mathbf{F}_{\text {30ST }}$ \\
\hline Onset decomposition $\left({ }^{\circ} \mathbf{C}\right)$ & 380 & 358.9 & 329.1 & 368.8 & 356.9 \\
$\mathbf{T}_{\max }\left({ }^{\circ} \mathbf{C}\right)$ & 425.7 & 427.5 & 430.2 & 427.9 & 429.6 \\
$\mathbf{V}_{\max }(\boldsymbol{\%} / \min )$ & 23.16 & 21.56 & 16.55 & 21.22 & 18.77 \\
Residual rate (\%) & - & 3.05 & 10.16 & 4.21 & 5.98 \\
\hline
\end{tabular}

\subsection{Mechanical analysis}

The evolution of the tensile strength of untreated and treated composites as a function of the rate of olive pomace flour is shown in Figure 5, with a decrease in the tensile strength of the composites with the increase in untreated olive pomace flour compared to PS, estimated at 14.1, 10.62 and $4.82 \mathrm{MPa}$ for the $\mathrm{F}_{10 \mathrm{UT}}, \mathrm{F}_{20 \mathrm{UT}}$ and $\mathrm{F}_{30 \mathrm{UT}}$ respectively. These results are attributed to the decrease in binding strength between the fiber and the matrix that obstructs stress propagation, which can be explained by the tendency of olive pomace flour particle store group by forming agglomerates that induce heterogeneities and non-uniform stress transfer within the matrix [15, 28-29].

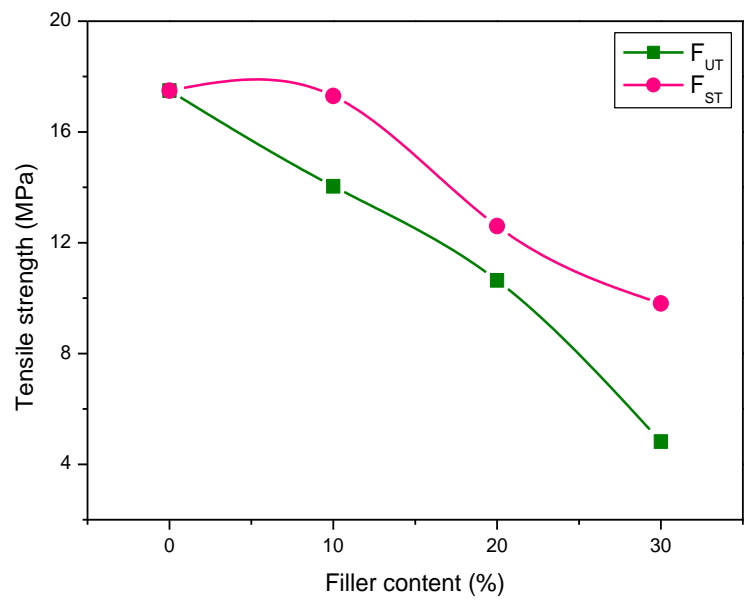

Figure 5. Tensile strength of PS and composites

After chemical treatment, we observe an improvement in tensile strength for composites treated with 3(trimethoxysilyl) propyl methacrylate compared to untreated composites. This increase is due to the better dispersion of the filler and particularly to the reinforcement of interfacial bonds between PS polystyrene and olive pomace flour. Explain by the ability of silane to form strong interfacial bonds between the PS and OPF and therefore a better stress transfer between matrix and olive flour $[17,30]$.

Figure 6 shows the evolution of the elongation at break of composites as a function of the load rate. There is a significant decrease in elongation at break as the load rate increases. It goes from $10.49 \%$ for the PS matrix to 3.96 3.49 , and $3.24 \%$ for composites to $10-20$ and $30 \%$ filler. This decrease is explained on the one hand by the hydrophilic nature of the untreated flour, which absorbs more moisture and causes swelling in the PS matrix, which causes the material to weaken, and on the other hand by the increasing volume of filler particles, creating defects in the system and reducing inter-chain interactions, associated with a ductile fragile variation in material behavior $[16,18]$. Comparing the elongations at break of the different composites, it can be clearly seen that the chemical treatment with the silane coupling agent brought a slight improvement, estimated at 5 3.6 and $3.3 \%$ for the $F_{10 S T}, F_{20 S T}$ and $F_{30 S T}$ formulations respectively but not in terms of overall deformation compared to the virgin PS. This increase is mainly attributed to a better dispersion of the processed flour, which gives the material certain flexibility $[19,31]$.

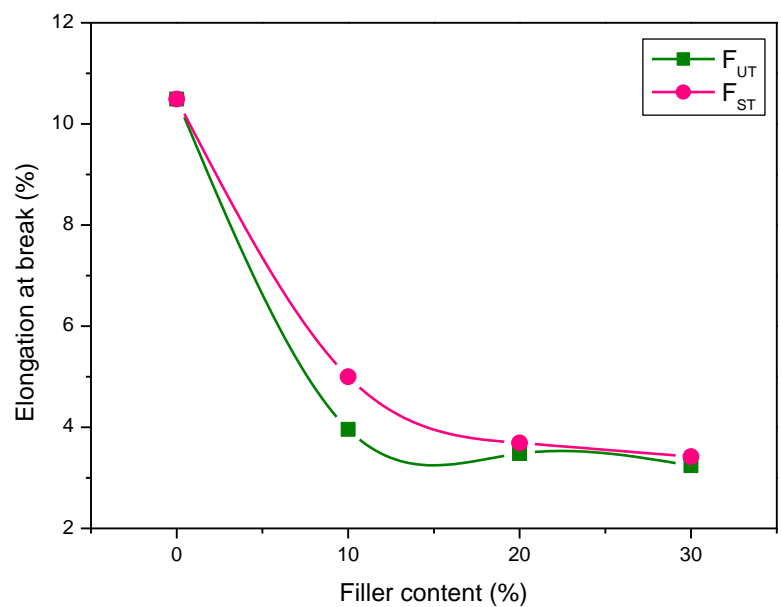

Figure 6. Elongation at break of PS and composites

The evolution of Young's modulus of composites is presented in Figure 7. We note that the introduction of untreated olive pomace flour into the polystyrene matrix increases the rigidity of the material. Young's modulus increases by $142 \mathrm{MPa}$ for virgin PS to reach $176-204$ and $249 \mathrm{MPa}$ for composites containing 10 - 20 and $30 \%$ of OPF. These results are attributed to the rigid phase of the dispersed olive pomace flour which gives high rigidity to the polymer matrix [22, 32]. Chemical treatment of flour with 3(trimethoxysilyl) propyl methacrylate significantly increases Young's modulus compared to untreated composites. This increase is mainly due to better fiber /matrix interfacial adhesion due to the good dispersion of the treated olive flour in the PS matrix. The treatment resulted in the formation of chemical bonds between the hydrophobic part of the silane 
and the matrix surface and the hydrophilic part with the flour surface $[18,33]$.

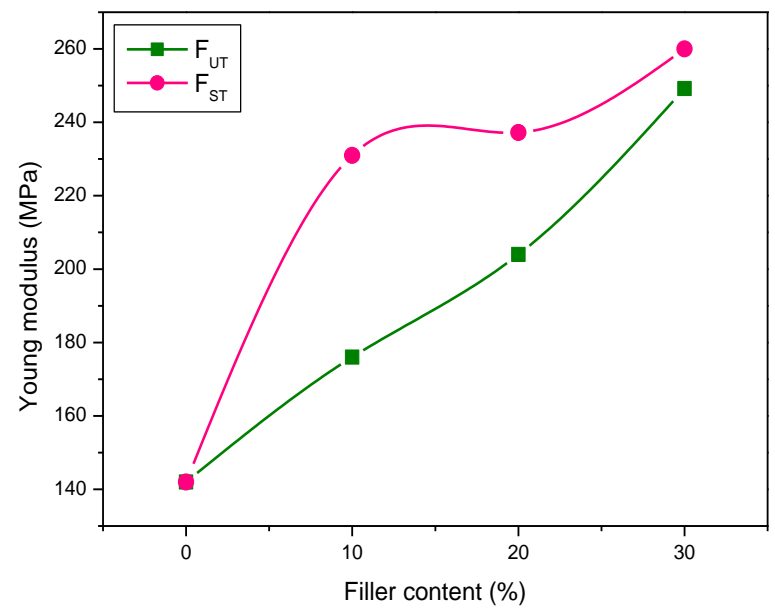

Figure 7. Young modulus of PS and composites

\section{CONCLUSIONS}

This study is devoted to the recovery of olive oil mill waste as filler in the elaboration of polystyrene composites. For the problem of interfacial fiber / matrix adhesion, 3(trimethoxysilyl) propyl methacrylate is used for the modification of the olive pomace flour coupling as a coupling agent.

The chemical composition informed that cellulose is the main component of olive pomace flour with a low density. The results of the FTIR analysis confirmed the grafting of the silane compound on the surface of the flour particles by the appearance of an absorption band in the region between 1050 and $1100 \mathrm{~cm}^{-1}$, characteristic of the vibrations of the Si-Ocell and $\mathrm{Si}-\mathrm{O}-\mathrm{Si}$ groups.

SEM analysis indicates that treated composites have better interfacial adhesion compared to untreated composites. Thermal analysis showed that the incorporation of untreated olive pomace flour into the PS matrix reduced the onset decomposition. On the other hand, there is again in the onset decomposition of treated composites. The mechanical behavior of the composites shows that with the increase in the rate of treated and untreated olive flour, stress and elongation at break decrease, while Young's modulus gradually increases.

\section{REFERENCES}

[1] Ichazo, M.N., Albano, C., Gonzalez,J., Perera, R., Candal, M.V. (2001). Polypropylene/wood flour composites: Treatments and properties. Composite Structures, 54(2-3): 207-214. https://doi.org/10.1016/S0263-8223(01)00089-7

[2] Seung-Hwan, L., Tsutomu, O. (2003). Mechanical and thermal flow properties of wood flour -biodegradable polymer composites. Journal of Applied Polymer Science, $\quad$ 90: 1900-1905. https://doi.org/10.1002/app.12864

[3] Torres, F.G., Cubillas, M.L. (2005). Study of the interfacial properties of natural fibre reinforced polyethylene. Polymer Testing, 24(6): 694-698. http://dx.doi.org/10.1016/j.polymertesting.2005.05.004

[4] Arrakhiz, F.Z., Elachaby, M., Bouhfid, R., Vaudreuil, S., Essassi, M., Qaiss, A. (2012). Mechanical and thermal properties of polypropylene reinforced with Alfa fiber under different chemical treatment. Materials and Design, 35: 318-322. http://dx.doi.org/10.1016/j.matdes.2011.09.023

[5] Rosa, S.M.L.R., Santos, E.F., Ferreira, C.A., Nachtigall, S.M.B. (2009). Studies on the properties of rice-huskfilled PP composites: Effect of maleated PP. Materials Research, 12: 333-338. http://dx.doi.org/10.1590/S1516-14392009000300014

[6] Poletto, M., Dettenborn, J., Pistor, V., Zeni, M., Zattera, A.J. (2010). Materials produced from plant biomass. Part I: Evaluation of thermal stability and pyrolysis of wood. Materials Research, 13: 375-379. http://dx.doi.org/10.1590/S1516-14392010000300016

[7] Kim, H.S., Lee, B.H., Choi, S.W., Kim, S., Kim, H.J. (2007). The effect of types of maleic anhydride grafted polypropylene (MAPP) on the interfacial adhesion properties of bio-flour filled polypropylene composites. Composites Part A: Applied Science and Manufacturing, 38(6): $1473-1482$ https://doi.org/10.1016/j.compositesa.2007.01.004

[8] Sain, M., Suhara, P., Law, S., Bouilloux, A. (2005). Interface modification and mechanical properties of natural fiber polyolef in composite products. Journal of Reinforced Plastics and Composites, 24: 121-130. https://doi.org/10.1177/0731684405041717

[9] Özmen, N. (2012). A study of the effect of acetylation on hemp fibres with vinyl acetate. BioResources, 7(3): 3800-3809.

[10] Manikandan, N.K.C., Sabu, T., Groeninckx, G. (2001). Thermal and dynamic mechanical analysis of polystyrene composites reinforced with short sisal fibres. Composites Science and Technology, 61(16): 25192529. https://doi.org/10.1016/S0266-3538(01)00170-1

[11] Bachtiar, D., Sapuan, S.M., Khalina, A., Zainudin, E.S., Dahlan, K.Z.M. (2012). Flexural and impact properties of chemically treated sugar palm fiber reinforced high impact polystyrene composites. Fibers and Polymers, 13: 894-898. https://doi.org/10.1007/s12221-012-0894-1

[12] Venkateshwaran, N., Peruma, A.E., Arunsundaranayagam, D. (2013). Fiber surface treatment and its effect on mechanical and visco-elastic behavior of banana / epoxy composite. Materials and Design, 47: 151-159. http://dx.doi.org/10.1016/j.matdes.2012.12.001

[13] Kakou, C.A., Arrakhiz, F.Z., Trokourey, A., Bouhfid, R., Qaiss, A., Rodrigue, D. (2014). Influence of coupling agent content on the properties of high density polyethylene composites reinforced with oil palm fibers. Materials and Design, 63: 641-649. http://dx.doi.org/10.1016/j.matdes.2014.06.044

[14] Singha, A.S., Raj, R.K. (2012). Natural fiber reinforced polystyrene composites: Effect of fiber loading, fiber dimensions and surface modification on mechanical properties. Materials and Design, 41: 289-297. http://dx.doi.org/10.1016/j.matdes.2012.05.001

[15] Asumani, O.M.L., Reid, R.G., Paskaramoorthy, R. (2012). The effects of alkali silane treatment on the tensile and flexural properties of short fibre non-woven kenaf reinforced polypropylene composites. Composites: 
Part A, 43(9): 1431-1440.

http://dx.doi.org/10.1016/j.compositesa.2012.04.007

[16] Merkel, K., Rydarowski, H., Kazimierczak, J., Bloda, A. (2014). Processing and characterization of reinforced polyethylene composites made with lignocellulosic fibres isolated from waste plant biomass such as hemp. Composites: Part B, 67: 138-144. http://dx.doi.org/10.1016/j.compositesb.2014.06.007

[17] Nekkaa, S., Guessoum, M., Benamara, R., Haddaoui, N. (2013). Influence of surface flour treatment on the thermal, structural and morphological properties of polypropylene / spartium junceum flour composites. Polymer-Plastics Technology and Engineering, 52: 175181. http://dx.doi.org/10.1080/03602559.2012.734363

[18] Xie, Y., Callum, A.S.H., Xiao, Z., Holger, M., Carsten, M. (2010). Silane coupling agents used for natural fiber / polymer composites: Areview. Composites: Part A, 41(7): 806-819. http://dx.doi.org/10.1016/j.compositesa.2010.03.005

[19] Abdelmouleh, M., Boufi, S., Belgacem, M.N., Dufresne, A. (2007). Short natural fibre reinforced polyethylene and natural rubber composites: Effect of silane coupling agents and fibres loading. Composites Science and Technology, 67(7-8): 1627-1639. http://dx.doi.org/10.1016/j.compscitech.2006.07.003

[20] Bledzki, A.K., Mamun, A.A., Lucka, G.M., Gutowski, V.S. (2008). The effects of acetylation on properties of flax fibre and its polypropylene composites. Express Polymer Letters, 2(6): 413-422. http://dx.doi.org/10.3144/expresspolymlett.2008.50

[21] Naghmouchi, I., Espinach, X.F., Mutjé, P., Boufi, S. (2015). Polypropylene composites based on lignocellulosic fillers: How the filler morphology affects the composite properties. Materials and Design, 65: 454-461. http://dx.doi.org/10.1016/j.matdes.2014.09.047

[22] Djidjelli, H., Benachour, D., Boukerrou, A., Zefouni, O., Martinez-Véga, J., Farenc, J., Kaci, M. (2007). Thermal, dielectric and mechanical study of poly(vinylchloride) / olive pomace composites. Express Polymer Letters, 1(22): 846-852. https://dx.doi.org/10.3144/expresspolymlett.2007.117

[23] Hassaini, L., Kaci, M., Touati, N., Pillin, I., Kervoelen, A., Bruzaud, S. (2017). Valorization of olive husk flour as a filler for biocomposites based on poly(3hydroxybutyrate-co-3-hydroxyvalerate): Effects of silane treatment. Polymer Testing, 59: 430-440. http://dx.doi.org/10.1016/j.polymertesting.2017.03.004

[24] Oumer, A.N., Bachtiar, D. (2014). Modeling and experimental validation of tensile properties of sugar palm fiber reinforced high impact polystyrene composites. Fibers and Polymers, 15: 334-339. https://doi.org/10.1007/s12221-014-0334-5

[25] Zizumbo, A., Licea-Claveríe, A., Lugo-Medina, E., García-Hernández, E., Madrigal, D., Zitzumbo, R. (2011). Polystyrene composites prepared with polystyrene graffed-fibers of sugar cane bagasse as reinforcing material. Journal of the Mexican Chemical Society, 55: 33-41.

[26] Hammoui, Y., Molina-Boisseau, S., Duval, A., Djerrada, N., Adjeroud, N., Remini, H., Dahmoune, F., Madani, K. (2015). Preparation of plasticized wheat gluten / olive pomace powder biocomposite: Effect of powder content and chemical modifications. Materials and Design, 87(15): http://dx.doi.org/10.1016/j.matdes.2015.08.080

[27] Monteiro, S.N., Calado, V., Rodriguez, R.J.S., Margem, F.M. (2012). Thermogravimetric stability of polymer composites reinforced with less common lignocellulosic fibers: An overview. Journal of Materials Research and Technology, 1(2): 117-126. https://doi.org/10.1016/S2238-7854(12)70021-2

[28] Sathishkumar, T.P., Navaneethakrishnan, P., Shankar, S., Rajasekar, R., Rajini, N. (2013). Characterization of natural fiber and composites - A review. Journal of Reinforced Plastics and Composites, 32: 1457-1476. https://doi.org/10.1177/0731684413495322

[29] Kaci, M., Djidjelli, H., Boukerrou, A., Zaidi, L. (2007). Effect of wood filler treatment and EBAGMA compatibilizer on morphology and mechanical properties of low density polyethylene / olive husk flour composites. Express Polymer Letters, 1(7): 467-473. https://doi.org/10.3144/expresspolymlett.2007.65

[30] Thao, T.P, Bénézet, J.C., Bergeret, A. (2014). Rice and Einkorn wheat husks reinforced poly(lacticacid) (PLA) biocomposites: Effects of alkaline and silane surface treatments of husks. Industrial Crops and Products, 58: 111-124. https://doi.org/10.1016/j.indcrop.2014.04.012

[31] Yu, T., Ren, J., Li, S.M., Yuan, H., Li, Y. (2010). Effect of fiber surface treatments on the properties of poly(lacticacid) / ramie composites. Composites: Part A, 41(4): https://doi.org/10.1016/j.compositesa.2009.12.006

[32] Sapuana, S.M., Bachtiar, D. (2012). Mechanical properties of sugar palm fibre reinforced high impact polystyrene composites. Procedia Chemistry, 4: 101106. https://doi.org/10.1016/j.proche.2012.06.015

[33] Nah, C., Hong, C.K., Hwang, I., Kim, N., Parkc, D.H., Hwang, B.S. (2008). Mechanical properties of silanized jute polypropylene composites. Journal of Industrial and Engineer,ing Chmistry, 14(1): 71-76. http://dx.doi.org/10.1016\%2Fj.jiec.2007.07.002

\section{NOMENCLATURE}

$\begin{array}{ll}\text { PS } & \text { Polystyrene matrix } \\ \text { OPF } & \text { Olive pomace flour } \\ \text { FUT }_{\text {UT }} & \text { Formulation with untreated Flour } \\ \text { F }_{\text {ST }} & \text { Formulation with treated Flour }\end{array}$

